\title{
Epidemiology and Prognosis of Retroplacental Hematoma in a Maternity Ward at a Regional Hospital Center in Southern Senegal
}

\author{
Babacar Biaye, Omar Gassama, Mame Diarra Ndiaye Gueye, Moussa Diallo, Aminata Niass, \\ Mor Cisse, Alassane Diouf, Jean Charles Moreau \\ Gynecological and Obstetric Clinic, University Hospital Aristide Le Dantec, Dakar, Senegal \\ Email: drbabacarbiaye@yahoo.fr
}

How to cite this paper: Biaye, B., Gassama, O., Gueye, M.D.N., Diallo, M., Niass, A., Cisse, M., Diouf, A. and Moreau, J.C. (2019) Epidemiology and Prognosis of Retroplacental Hematoma in a Maternity Ward at a Regional Hospital Center in Southern Senegal. Open Journal of Obstetrics and Gynecology, 9, 149-157.

https://doi.org/10.4236/ojog.2019.92016

Received: December 28, 2018

Accepted: January 30, 2019

Published: February 2, 2019

Copyright $\odot 2019$ by author(s) and Scientific Research Publishing Inc. This work is licensed under the Creative Commons Attribution International License (CC BY 4.0).

http://creativecommons.org/licenses/by/4.0/

\section{(c) (i) Open Access}

\begin{abstract}
Objectives: To study the epidemiological profile and the prognosis of the retro-placental hematoma (HRP) at the maternity ward at Kolda Regional Hospital Center. Materials and methods: This was a retrospective descriptive cross-sectional study conducted over a period of 11 years: from January $1^{\text {st }}$, 2006 to December 31 ${ }^{\text {st }}, 2016$, at Kolda Regional Hospital Center. It included all patients admitted for HRP during this period. The studied parameters concerned sociodemographic characteristics, gynecological obstetrical history; clinical, therapeutic and prognostic data (non-inclusion or exclusion criteria). The data were collected from medical records, the delivery room and the surgery room registers using a collection sheet developed for this purpose. The statistical analysis of the variables studied was done with the software Epi-info 3.5. For the qualitative variables, we calculated the frequencies and for the quantitative variables, we studied the distributions. Results: During the study period, 15,343 were recorded deliveries and we carried out the diagnosis of HRP in 301 patients (1.97\%). The average age of the patients was 24 years with an average parity of 4.8 deliveries. Almost all the patients $(87.5 \%)$ were evacuated and half had delivered by caesarean section. Maternal and fetal deaths were $7 \%$ and $72.1 \%$, respectively. Uterine atony accounted for $21.2 \%$ of complications. One third of the cases of uterine atony had resulted in a hysterectomy. The average duration of hospitalization was 6 days. Conclusion: The retro-placental hematoma is a serious medico-obstetric emergency. It is burdened with high maternal and fetal morbidity and mortality in developing countries.
\end{abstract}

\section{Keywords}

Retro-Placental Hematoma, Mortality, Kolda 


\section{Introduction}

The retroplacental hematoma (HRP) is the premature detachment of the normally inserted placenta while the fetus is still in utero. Its frequency is variously appreciated according to the authors: $0.25 \%$ in Europe [1] [2] [3], $1 \%$ to $9 \%$ in developing countries [4] [5] [6]. This is a major obstetric complication with significant maternal and perinatal morbidity and mortality. The fetal complications are intrauterine growth retardation, especially induced prematurity and its complications. The most common maternal complications are hemorrhagic shock, haemostasis disorders and less rarely maternal deaths. In this, care is multidisciplinary.

In fact, the obstetrical treatment consists of a rapid uterine evacuation and the delivery route is mainly a function of the labor phase and the foeto-maternal status. The pre and post partum resuscitation is always necessary as well as pediatrician involvement.

The objective of this study is to evaluate the epidemiological profile and the prognosis of the retro-placental hematoma (HRP) at the maternity ward at Kolda Regional Hospital Center.

\section{Patients and Methods}

We conducted a retrospective descriptive cross-sectional study from January $1^{\text {st }}$, 2006 to December 31 $1^{\text {st }}, 2016$ at Kolda Regional Hospital Maternity Hospital. It was a Level II maternity hospital, the only Regional Hospital Center in Kolda located on average Casamance (700 km from the capital) and border to the Republic of Guinea Bissau. All health centers in the Kolda region, as well as some in the Sedhiou region and some health posts in Guinea Bissau, evacuated to this structure.

This study included all patients presented clinical signs of HRP in the service regardless of the delivery route during the study period. Patients whose care required evacuation outside the hospital were not included. The parameters studied were as follows: age, parity, mode of admission, existence or absence of uterine scar, term of pregnancy, history of hypertension, mode of entry to work, the mode of delivery, clinical data, maternal-fetal complications and therapeutic aspects.

The severity of the clinical picture was assessed according to the SHER classification, we distinguish: grade 1: seemingly isolated metrorrhagia; grade 2: more complete symptomatology and living child; grade 3: complete symptomatology with fetal death (3A: without coagulation disorders; 3B: with coagulation disorders).

The APGAR score $\leq 6$ defined perinatal asphyxia. This data was collected through the patient's medical records, the birth room and operating room registers. The descriptive statistical analysis was carried out with the Epi-info software. The distributions of the quantitative variables and the proportions of the qualitative variables were calculated. 


\section{Results}

\section{1) Socio-demographic characteristics}

During this period of study, we recorded 15,343 deliveries, comprising 301 cases of retroplacental hematoma representing a frequency of $1.97 \%$.

The average age of the patients was 24 years with extremes of 16 and 43 years. The average parity was 4.8 deliveries with extremes of 1 and 13 deliveries. The majority of patients (85.7\%) came from surrounding health structures, particularly from the Kolda region (77.7\%), Sédhiou (15.9\%) and the Republic of Guinea Bissau (6.3\%) (Table 1).

\section{2) Clinical data}

A bit less than one-third of cases (29\%) presented chronic arterial hypertension that was not followed or poorly monitored (Table 1 ).

Six (6.9\%) patients had never had prenatal consultation (ANC) and only $10.4 \%$ of our patients completed the 4 ANC recommended by WHO.

Mean gestational age was 36 weeks of amenorrhea (AS) and 3 days with extremes of 24 and 40 weeks of amenorrhea. Prematurity accounted for $43 \%$ of cases.

The diagnosis of HRP focused on the clinical database.

Table 1. Epidemiological characteristics of patients.

\begin{tabular}{|c|c|c|}
\hline Characteristics & Number & Percentage \\
\hline \multicolumn{3}{|l|}{ Age } \\
\hline$<20$ & 41 & $13.6 \%$ \\
\hline 20 to 24 & 69 & $22.9 \%$ \\
\hline 25 to 29 & 92 & $30.6 \%$ \\
\hline 30 to 34 & 48 & $15.6 \%$ \\
\hline 35 to 39 & 44 & $14.6 \%$ \\
\hline$\geq 40$ & 7 & $2.3 \%$ \\
\hline \multicolumn{3}{|l|}{ Parity } \\
\hline Primipare & 42 & $13.9 \%$ \\
\hline Paucipare & 58 & $19.6 \%$ \\
\hline Multiparous & 89 & $29.6 \%$ \\
\hline Grande multiparous & 112 & $37.2 \%$ \\
\hline \multicolumn{3}{|l|}{ Admission criteria } \\
\hline Patients who came on their own & 43 & $14.3 \%$ \\
\hline Evacuated patients & 258 & $85.7 \%$ \\
\hline \multicolumn{3}{|l|}{ Address } \\
\hline Kolda & 234 & $77.7 \%$ \\
\hline Sédhiou & 48 & $15.9 \%$ \\
\hline Guinée Bissau & 19 & $6.3 \%$ \\
\hline
\end{tabular}


For the majority of patients $(87 \%)$, the clinical signs at admission were dominated by metrorrhagia (97.7\%), uterine hypertonia $(77.1 \%)$, and absence of fetal heart activity (76\%), (1\%) and shock (10\%) (Table 2).

Forty percent $(40 \%)$ of the patients had hypertension on admission, half pre-eclamps. Almost all patients (93.5\%) had spontaneously entered work. The most frequent table was grade 3: 226 cases (75.1\%). Coagulopathy was observed in $8 \%$ of patients (Table 3 ).

\section{3) Therapeutic and prognostic aspects}

Caesarean section delivery accounted for $51.2 \%$ of the sample. The perinatal mortality was high; it concerned $76.1 \%$ of the fetuses. Perinatal asphyxia made $19 \%$ of births complicated. Maternal morbidity was dominated by anemia (227 cases) followed by renal failure (20\%), HELLP syndrome (19\%), and uterine atony 32 cases (10\%) (Table 4$)$.

The management of uterine atony consisted of medical treatment in $(21.8 \%)$ cases, conservative surgery for (40.6\%) and hysterectomy in (37.5\%). Among the cases of uterine atony, seven received medical treatment with misoprostol, thirteen underwent a conservative surgical technique (arterial ligation and/or B-Lynch compression) and twelve underwent haemostatic hysterectomy.

The specific lethality of HRP was 7\%. Eighty-six percent of the deceased patients were discharged and $62 \%$ were classified as SHER Stage III. The average duration of hospitalization was 6 days.

Table 2. Distribution of patients according to the clinical picture.

\begin{tabular}{ccc}
\hline Clinical sign & Number & Percentage \\
\hline Metrorrhagia & 294 & $97.7 \%$ \\
Uterine hypertonia & 232 & $77.1 \%$ \\
Absence of cardiac activity & 229 & $76.1 \%$ \\
Shock condition & 30 & $10 \%$ \\
\hline
\end{tabular}

Table 3. Distribution of patients by SHER classification [7].

\begin{tabular}{ccc}
\hline Stage & Number & Percentage \\
\hline Stage I & 13 & $4.3 \%$ \\
Stage II & 62 & $20.6 \%$ \\
Stage III a & 202 & $67.1 \%$ \\
Stage III b & 24 & $8 \%$ \\
\hline
\end{tabular}

Table 4. Distribution by morbidity.

\begin{tabular}{ccc}
\hline Morbidity & Number & percentage \\
\hline Anemia & 227 & $75.4 \%$ \\
Renal failure & 63 & $20.9 \%$ \\
Hellp syndrome & 57 & $18.9 \%$ \\
Coagulopaty & 32 & $10.6 \%$ \\
Uterine atrophy & 32 & $10.6 \%$ \\
\hline
\end{tabular}




\section{Discussion}

\section{1) Socio-demographic characteristics}

In Senegal there is no study evaluating the incidence of retroplacental hematoma at the national level. In our study, the frequency of HRP is $1.97 \%$. This rate is slightly lower than other studies in other regions of Senegal. Thus, Thiam [7] in Ndioum found a rate of 6\%, and Dumont [8] in Saint Louis reports an incidence of $4.2 \%$. In Africa, particularly in Cameroon and Gabon, studies found respectively 3.84 and 2.44 [4] [9]. In France, the frequency of HRP varies between 0.25 and $0.5 \%$ [1].

These differences are due, on the one hand, to the diversity of classifications used by these authors, a complete picture including anatomopathology, or a simple macroscopic or microscopic finding, or even a purely clinical diagnosis. On the other hand, sociodemographic, economic and environmental characteristics (climatic, seasonal factors, eating habits) noted by these authors, [10] [11] [12] [13] have contributed to the increase in the frequency of HRP.

\section{2) Clinical data}

The average age of HRP was 24 years old and the most represented age group was 25 to 30 years old. This age is slightly lower than that found by studies in Senegal and Africa [5] [7] [11] [12] $(29.9,29.8,29.6,30)$. This average age can be explained, in part by early marriage in this part of Senegal.

Several studies have shown that multiparity is a risk factor for HRP [14] [15] [16]. The average parity in our series was 4.8 deliveries and multiparas accounted for almost $66 \%$. This rate is close to that of THIAM, where the average parity was 4.8 deliveries with $58 \%$ multipare [7]. However, this rate is higher than that of the developed countries [17] [18]. This, can be explained by a late pregnancy but also a birth limitation in developed countries contrary to our context.

In our series $85 \%$ of the patients were evacuees, similar rate to THIEBA (85.9\%), OUEDRAOGO (88\%), SARR (83\%). This mode of admission constitutes a factor of poor maternal and fetal prognosis in Dakar. Indeed the Hospital Center absorbs all the evacuations of the region as well as those of the border structures.

The average age at which HRP occurred was 36 weeks +3 days, and only $10 \%$ of patients completed the 4 prenatal consultations recommended by WHO [19].

The number of CPNs performed is variously appreciated by the authors; however, all agree that the frequency of HRP is inversely proprotional to the number of ANC [3] [5] [7] [19].

The occurrence of HRP in a hypertensive context is noted by many authors [15] [16] [19]. In our series, we found $40 \%$ of vasculo-renal syndrome cases. Our results are similar to those of Nyama [10] who found a rate of $39.8 \%$.

However, our rate is much higher than that of other authors including Ananth et al. [20], Oyelese [21] and Toivonen et al. [22] who found respectively $14 \%$, $12.12 \%$ and $2.3 \%$. 
Clinically, we found metrorrhagia in $97.7 \%$ of cases, uterine hypertonicity in $77.1 \%$, absence of fetal heart activity in $76.1 \%$ of cases and shock in $10 \%$ of cases. Due to the absence of an ultrasound machine in the work room, the ultrasound diagnosis was not done in any of the patients (more discuss the effectiveness of the clinical diagnosis) (there are publications on the clinical diagnosis).

Ouédraogo in Burkina, found a lack of fetal heart activity (82\%), uterine hypertonicity $(79.8 \%)$, metrorrhagia $(74.2 \%)$ [11]. On the other hand, in Western countries, $10 \%$ to $20 \%$ of placental abruption was made complicated because of intrauterine fetal death [16] [20] (Table 5).

\section{3) Therapeutic and prognostic aspects}

In our series, $51.1 \%$ of patients had delivered by cesarean section. Ouédraogo in Burkina Faso found 64\% of normal delivery versus $36 \%$ of cesarean section [11]. However, Doumbia in Côte d'Ivoire and Nayama in Niger have a higher cesarean section rate of $63.2 \%$ and $94.10 \%$, respectively [6] [10]. These differences can be explained by differences in treatment protocols. It is important to note that a large proportion of the patients that were admitted at center were in labour. Early, rapid uterine evacuation and resuscitation are the basis of treatment for retroplacental hematoma. However, the way of delivery is not unanimous.

Some authors including Krauss et al. [23] and Prochazka et al. [24] advocate systematic caesarean section regardless of the condition of the fetus. In contrast, Bohec et al. [1] recommends a wait-and-see attitude to HRP with fetal death and bleeding disorders. In developing countries, such as Senegal, where the technical plateau is low and taking into account the conditions and time of admission of patients, we believe that the expectant attitude in the event of fetal death is not indicated given the insufficiency in available blood products and in human and financial resources to manage severe anemia, hypovolemic shock and DIC. A better endowment of consumable products (fill fluids), blood products, and adequate equipment for the laboratory service and, above all, the availability of qualified and sufficient staff are essential to reduce the rate of caesarean section in case of HRP in our service. This could promote acceptance of vaginal delivery, especially in cases of fetal death.

As in most African studies [6] [7] [12] [13], maternal morbidity was dominated by anemia in our series (75.4\%), anemia occurring on a site weakened by multiparity and social conditions. and precarious economics.

Table 5. Distribution of the clinical picture according to the studies.

\begin{tabular}{cccc}
\hline Surveys & Fetal death & Metrorrhagia & Hypertonia \\
\hline Our series & $76.1 \%$ & $97.7 \%$ & $77.1 \%$ \\
Ouedraougo [11] (Niger 2015) & $82 \%$ & $74.2 \%$ & $79.8 \%$ \\
Ananth [18] (USA 2010) & $16.1 \%$ & $71.1 \%$ & $27.8 \%$ \\
Boisrame [16] (France2011) & $12 \%$ & $67 \%$ & $4 \%$ \\
\hline
\end{tabular}


In our series we found 32 cases of uterine atony of which $37.5 \%$ had a hysterectomy of haemostasis.

We recorded high lethality (7\%) compared to other counts (2\% - 5\%) [10] [11]. This can be explained by a delay of support but also by the insufficiency of the technical platform.

The fetus pays the highest price to the HRP in our African countries [9] [10] [11]. Perinatal mortality remains high and is $76.1 \%$ in our series. Our figures are slightly higher than those of Nayama (71.3\%), against Ouédraogo has recorded a higher rate $(86.7 \%)$. Some African writers have found that medical evacuation and the extent of the detachment surface are poor prognostic factors.

\section{Conclusion}

The retro placental hematoma remains a major medico-obstetric emergency in our practice. Diagnosis and early management improve the prognosis. The prevention of maternal and fetal mortality related to this condition requires an improvement in prenatal consultation, a better organization of the delivery plan, especially in the peripheral maternity ward, and an improvement in evacuation conditions, especially in rural areas where the means are limited.

\section{Conflicts of Interest}

The authors declare no conflicts of interest regarding the publication of this paper.

\section{References}

[1] Bohec, C. and Collet, M. (2015) Abruptio Placentae. Annales Françaises d Anesthésie et de Réanimation, 29, 115-119. https://doi.org/10.1016/j.annfar.2010.03.011

[2] Kikutani, M., Ishihara, K. and Araki T. (2003) Value of Ultrasonography in the Diagnosis of Placental Abruption. Journal of Nippon Medical School, 70, 227-233. https://doi.org/10.1272/jnms.70.227

[3] Cande, V. and Wilcox, J. (2001) Placental Abruption and Perinatal Mortality in the United States. American Journal of Epidemiology, 153, 332-336. https://doi.org/10.1093/aje/153.4.332

[4] Akpadza, K., Baeta, S., Neglo, Y., Tete, U. and Hodomou, A.K. (1996) L'hématome rétroplacentaire (HRP) à la clinique gynécologique du CHU de Tokoin. Médecine Afrique Noire, 43, 342-347.

[5] Gaye, A., Dumont, A., De Bernis, L. and Diadhiou, F. (2002) L'hématome retro placentaire au Centre de santé Roi Baudouin à Dakar: Prise en charge et pronostic. Journal de la $S A G O, 1,1519$.

[6] Doumbia, Y., Kouakou, K.P., Djanhan, L.E., Menin, M.M., Kone, D.D.A. and Djanhan, Y. (2013) The Placental Abruptionat the Bouaké University Hospital: About 524 Cases. Journal of SAGO, 14, 39-44.

[7] Thiam, O., Mbaye, M., Diouf, A.A., Touré, F.B., Gaye, M., Niang, M., Cissé, L.M., Dièye, S. and Moreau, J.C. (2014) Prognostic and Therapeutic Epidemiological Aspects of Placental Abruption in a Maternityreferral in Rural Area (RHC de Ndioum). The Pan African Med ical Journal, 17. 
[8] Dumont, A., De Bernis, L., Decame, C., Ba, M. and Pollet, X. (1996) Indicateurs de la coagulation intravasculaire disséminée (CIVD) dans les hématomes retroplacentaires. Médecine Afrique Noire, 43, 611.

[9] Younbessi, T.J., Kenmogne, F. and Fomulu, N. (1987) Complications fotomaternelles liées aux maladies hypertensives de la grossesse chez la femme camerounaise. Médecine Afrique Noire, 47, 621-628.

[10] Nayama, M., Tamakloé-Azamesu, D., Garba, M., Idi, N., Djibril, B. and Houfflin-Debarge, V. (2007) Management in a Reference Nigerien Maternity. Prospective Study about 118 Cases during One Year. Gynecology and Obstetrics and Fertility, 35, 975-981. https://doi.org/10.1016/j.gyobfe.2007.05.023

[11] Ouédraogo, I., Sawadogo, Y.A., Kain, D.P., Zamane, H., Sib, S.R., Thieba, B. and Lankoandé, J. (2017) Placental Abruption in the Obstetrics and Gynecology Service of Regional Hospital Center of Ouahigouya: Epidemiological, Clinical Ant and Therapeutic Aspects about 89 Cases Collected from 1st January 2013 to 31st December 2015. Open Journal of Obstetrics and Gynecology, 7, 86-94.

https://doi.org/10.4236/ojog.2017.71010

[12] Sarr, F.R., Diouf, A., Cissé, M.L., Faye, E.O. and Moreau, J.C. (2003) Management and Prognosis of Placental Abruption in a University Hospital Center in Dakar, Senegal. Journal of SAGO, 5, 6-11.

[13] Thiéba, B., Lankoandé, J., Akotionga, M., Koné, B., Ouédraogo, A. and Kyelem, C. (2003) The Placental Abruption in the Gynecology and Obstetrics Department of the National Hospital Center Yalgado Ouédraogo of Ouagadougou: Epidemiological, Clinical and Prognostic Aspects. Gynécologie Obstétrique \& Fertilité, 31, 429-433.

[14] Tikkanen, M., Luukkaala, T., Gissler, M., Ritvanen, A., Ylikorkala, O. and Paavonen, J. (2012) Decreasing Perinatal Mortality in Placental Abruption. Acta Obstetricia et Gynec Ologica Scandinavica, 92, 298-305. https://doi.org/10.1111/aogs.12030

[15] Gueneuc, A., Carles, G., Lemonnier, M., Dalah, F. and Jolivet, M. (2015) Hématome rétroplacentaire: Térrain et facteurs pronstics revisitées à propos d'une série de 171 cas en Guyane Française. Journal de Gynécologie Obstétrique et Biologie de la Reproduction, 45, 1-7.

[16] Boisrame, T., Sananés, N., Fritz, G., Boudier, E., Viville, B. and Aissi, G. (2014) hématome rétroplacentaire. Diagnostic, prise en charge et pronostic maternofoetal. étude rétrospective de 100 cas. Gynécologie Obstétrique \& Fertilité, 42, 78-83.

[17] Denise, A.E., Cande, V.A., Vinay, P. and Anthony, M.V. (2010) Diagnosis of Placental Abruption: Relationship between Clinical and Histopathological Findings. European Journal of Obstetrics \& Gynecology and Reproductive Biology, 148, 125-130. https://doi.org/10.1016/j.ejogrb.2009.10.005

[18] Ananth, C.V., Peltier, M.R., Moore, D.F., et al. (2008) Reduced Folate Carrier 80A!G Polymorphism, Plasma Folate, and Risk of Placental Abruption. Human Genetics, 124, 137-145. https://doi.org/10.1007/s00439-008-0531-7

[19] WHO (2009) Women and Health: The Reality of Today's Program of Tomorrow. Information Report, $94 \mathrm{p}$.

[20] Ananth, C.V., Elsasser, D.A., Prasad, V., et al. (2010) Diagnosis of Placental Abruption. Relationship between Clinical and Histopatohological Finding. European Journal of Obstetrics \& Gynecology and Reproductive Biology, 148, 125-130. https://doi.org/10.1016/j.ejogrb.2009.10.005

[21] Oyelese, Y. and Ananth, C.V. (2006) Placental Abruption. Obstetrics \& Gynecology, 108, 1005-1016. https://doi.org/10.1097/01.AOG.0000239439.04364.9a 
[22] Toivonen, S., Heinonen, S., Anttila, M., Kosma, V.M. and Saarikoski, S. (2002) Reproductive Risk Factors, Doppler Findings, and Outcome of Affected Births in Placental Abruption: A Population-Based Analysis. American Journal of Perinatology, 19, 451-460. https://doi.org/10.1055/s-2002-36868

[23] Krauss, T., Rath, W. and Kuhn, W. (1993) Maternal and Fetal Morbidity and Mortality in Premature Abruptio Placentae. A Retrospective Analysis. Geburtshilfe Frauenheilkd, 53, 194-197.

[24] Prochazka, M., Happach, C., Marsal, K., Dahlback, B. and Lindqvist, P.G. (2003) Factor V Leiden in Pregnancies Complicated by Placental Abruption. BJOG, 110, 462-466. https://doi.org/10.1046/j.1471-0528.2003.02369.x 